\title{
Variable presentations of systemic lupus erythematosus based on presence or absence of antidouble stranded DNA antibodies: A case series
}

\author{
Somnath Maitra1, Swapan Sarkar², Biswaroop Mukherjee ${ }^{3}$, Suprotim Ghosh ${ }^{4}$ \\ ${ }^{1,2,3}$ Associate Professor, ${ }^{4}$ Post Graduate Trainee, Department of General Medicine, Jagannath Gupta Institute of \\ Medical Sciences and Hospital, Kolkata, West Bengal, India
}

Systemic lupus erythematosus (SLE) presents with diverse clinical features causing diagnostic challenges. Apart from the clinical features, autoantibodies are important for diagnosis along with certain laboratory parameters. Diagnosis is made with the European League against Rheumatism/American College of Rheumatology 2019 Criteria. The case series presented here signifies the correlation between anti ds DNA positivity and its association with poor prognosis and renal disease, whereas antidouble stranded DNA (anti-dsDNA) negativity may lead to lack of renal involvement and may be associated with polyserositis. The importance lies in the fact that these patients with anti-dsDNA negativity should be followed up for assessing conversion to positivity of anti-dsDNA, thus altering the prognosis and leading to renal involvement. Moreover, anti-SSA positive SLE patients must be followed up for possible development of sicca symptoms.

Key words: Anti-double stranded DNA; Kidney; Systemic lupus erythematosus
http://nepjol.info/index.php/AJMS DOI: 10.3126/ajms.v13i1.40369

E-ISSN: 2091-0576

P-ISSN: 2467-9100

Copyright (c) 2022 Asian Journal of Medical Sciences

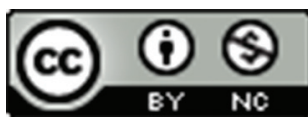

This work is licensed under a Creative Commons Attribution-NonCommercial 4.0 International License.

\section{INTRODUCTION}

Systemic lupus erythematosus (SLE) is a connective tissue disorder with multi system involvement. It produces various autoantibodies resulting from activation of polyclonal B cells. ${ }^{1-5}$ Antidouble stranded DNA antibodies (Anti-dsDNA antibodies) are specific for lupus. ${ }^{6}$ As they are highly sensitive $(57.3 \%)$ and specific $(97.4 \%)$, they are the diagnostic hallmark of SLE. ${ }^{2,6}$ Their presence is very rare in healthy persons. ${ }^{7}$ Anti-dsDNA may be detected several years before onset of disease. ${ }^{8}$ Anti-dsDNA antibodies are associated with renal involvement being deposited in glomeruli, sub endothelium, sub epithelium, mesangium, basement membranes, and tubules. ${ }^{9}$ Anti-dsDNA may also lead to activation of B and
T cells releasing pro inflammatory cytokines. ${ }^{10}$ Rise of levels may also lead to relapse of kidney disease..$^{11,12}$

Surprisingly, $2-30 \%$ of SLE patients have negative result for anti-dsDNA. ${ }^{7}$ Patients negative for anti-dsDNA have higher chance of polyserositis. Anti-SSA positivity as in cases 2 and 3 are associated with sicca symptoms and anti ribonucleoprotein is associated with Raynaud's phenomenon. ${ }^{7}$ Moreover, low C4 levels link anti-ds DNA and complements in renal disease. ${ }^{13}$ Anti-dsDNA negative cases with anti SSA and SSB positivity have higher chances of presenting with serositis. ${ }^{714}$ Our case series presents three cases of SLE with different clinical features based on presence or absence of anti-dsDNA antibodies. 
Case 1

A 50-year-old non-diabetic, non-hypertensive female, housewife by occupation presented with dyspnea on exertion with generalized weakness for the past 2 months without any history of fever, vomiting, loose motions, weight loss, and loss of appetite. There was no history of rashes, arthralgia or any bladder bowel symptoms. There was no history of bleeding from any site, nor any history of addiction or medication or abortion.

On General Survey, there was mild anemia with pitting edema in both lower limbs. There was no skin lesion or lymphadenopathy. Fever was not present, but petechial spots were present in the soft palate. Systemic examination revealed no abnormality. Examination of joints was normal.

A provisional diagnosis of immunogenic thrombocytopenic purpura was made with differentials of hypoplastic anemia and myelodysplastic syndrome.

Laboratory investigations revealed mild anemia with hemoglobin of $10 \mathrm{~g} / \mathrm{dl}$ with normal white blood cell count, but platelet count was $90,000 / \mathrm{mm}^{3}$. Urea, creatinine, sodium, and potassium were normal with mild transaminitis on liver function test (LFT). Hypoalbuminemia was present with albumin of $3.1 \mathrm{~g} / \mathrm{dl}$ and globulin of $3.3 \mathrm{~g} / \mathrm{dl}$. Rhematoid factor, anti-cyclic citrullinated peptide (CCP) antibody were negative, but anti-nuclear antibody (ANA) was positive by human epithelial type 2 (HEP 2) (1:80) and pattern was homogenous. Anti-dsDNA was positive by enzyme-linked immunosorbent assay (ELISA). AntiSm, Anti SS-A, SS-B, Ro52, Scl70, PM-Scl, Jo-1, CENP B, PCNA, Nucleosomes, Histones, Ribosomal-P Protein, and AMA-M2 were all negative. C3 was reduced with normal C4 levels. $24 \mathrm{~h}$ urinary protein was $1 \mathrm{~g} / 24 \mathrm{~h}$. C-reactive protein (CRP) was raised. Serology was non-reactive and peripheral blood smear revealed normocytic normochromic anemia. Vitamin B12 and red blood cell folate levels were normal. Ultrasound (USG) whole abdomen, chest X-ray, and echocardiography revealed no abnormality. Bone marrow revealed increase in number of megakaryocytes. Bleeding and clotting parameters were normal.

A diagnosis of SLE was done based on 2019 European League Against Rheumatism/American College of Rheumatology (EULAR/ACR) Classification criteria for SLE (Score $\geq 10$ ) based on positive anti-ds-DNA-6, low $\mathrm{C} 3=3$, thrombocytopenia-4, and raised 24 h urinary protein excretion-4. (17 points as SLE is diagnosed with $\geq 10$ points).

Patient was started on oral prednisolone $60 \mathrm{mg}$ OD. Platelet counts started to rise 3 days after starting steroids and were normal on day 10 of admission, when the patient was discharged. Patient is now in follow-up in the department of rheumatology.

\section{Case 2}

A 51 years old non-diabetic, non-hypertensive female, fruit seller by occupation presented with symmetrical inflammatory polyarthritis involving metacarpophalangeal (MCP) and proximal interphalangeal (PIP) joints of both upper limbs for 1 year. There was history of generalized weakness for the past 8 months without any history of fever, night sweats, weight loss, loss of appetite, vomiting, diarrhea, and pain abdomen. There was neither any history of rashes nor any history of abortions. History of alopecia was present for the past 9 months. There was no history of dryness of eyes.

On clinical examination mild pallor was present with non scarring alopecia. Systemic examination revealed pain on MCP and PIP joints with swelling and restriction of movements. Other systems did not reveal any abnormality. A provisional diagnosis of rheumatoid arthritis (RA) was made with a differential diagnosis of collagen vascular disease.

Investigations revealed hemoglobin of $10.5 \mathrm{~g} / \mathrm{dl}$ with leukopenia (total leukocyte count [TLC]-3500/ $\mathrm{mm}^{3}$ ) with normal platelet counts, renal function tests were normal with normal thyroid profile. Erythrocyte sedimentation rate (ESR) was $40 \mathrm{~mm}$ in $1^{\text {st }} \mathrm{h}$ with CRP of $2 \mathrm{U} / \mathrm{L}$. Urine examination was normal. Rheumatoid factor and anti-CCP antibody did not reveal any abnormality. LFT revealed mild hypo albuminemia. Bleeding and clotting parameters were normal. USG whole abdomen, chest X-ray, electrocardiogram, and echocardiography were normal. Serum ANA was positive by HEP 2 (1:80) and pattern was mixed. $(3+)$. ANA profile revealed positivity of anti-SSA. However, anti-ds DNA was negative. AntiSm, Anti SS-B, Ro52, Scl70, PM-Scl, Jo-1, CENP B, PCNA, Nucleosomes, Histones, Ribosomal-P Protein, and AMA-M2 were all negative.

A diagnosis of SLE was made by EULAR/ACR2019 Criteria (non scarring alopecia=2, joint involvement-6, and leukopenia=3). SLE was diagnosed with 11 points as $\geq 10$ points is diagnostic of SLE. Patient was started on steroids with clinical improvement and is now undergoing follow-up in rheumatology clinic.

\section{Case 3}

A 31 year old non-diabetic, non-hypertensive female presented with photosensitivity and malar rash for past 5 months with non-scarring alopecia for similar duration. There was no history of fever, night sweats, weight loss, loss of appetite, vomiting, and loose motions. There was 
no history of abortions, arthralgia, arthritis, and bleeding manifestations. There was no history of dryness of eyes, dysphagia, or swelling of neck. Treatment history was insignificant and the patient did not have any addiction. Menstrual history was unremarkable.

On clinical examination, there was malar rash involving the bridge of the nose without any oral ulcer. There was mild pallor without any lymphadenopathy. Systemic examination was unremarkable. A provisional diagnosis of collagen vascular disease was made.

Investigations revealed mild pallor with leukopenia (TLC$3700 / \mathrm{mm}^{3}$ ) with normal LFT and renal function tests. ESR was $20 \mathrm{~mm}$ in $1^{\text {st }} \mathrm{h}$ and CRP was $3 \mathrm{U} / \mathrm{L}$. Chest X-ray revealed mild bilateral pleural effusion with mild pericardial effusion on echocardiography. USG whole abdomen was normal with normal prothrombin time, activated partial thromboplastin time, and international normalized ratio. Urine examination was normal.

ANA HEP 2 was positive 1:80 titer and pattern was mixed with ANA profile showing anti SS A Positivity (2+), but anti-dsDNA was negative. Anti-Sm, Anti SS-B, Ro52, Scl70, PM-Scl, Jo-1, CENP B, PCNA, Nucleosomes, Histones, Ribosomal-P Protein, and AMA-M2 were all negative. C3 level was low $(0.7 \mathrm{~g} / \mathrm{l})(0.9-1.8)$, with normal C4.

Diagnosis of SLE was made by EULAR/ACR 2019 criteria (leukopenia-3, pleural and pericardial effusion-5, low C3-3 and thus 11 points diagnosed SLE with $\geq 10$ points) and patient was started on steroids and hydroxychloroquine. The pericardial effusion improved after starting steroids which is evident from Figures 1 and 2. The patient is now under rheumatology follow-up.

\section{DISCUSSION}

SLE presents with various clinical features. It is associated with many auto-antibodies with formation and deposition of immune complex. The new classification reflects pathogenesis of SLE and gives importance to ANA with high sensitivity and limited specificity. The three cases presented here had different manifestations. The first case presented as idiopathic thrombocytopenic purpura (ITP) with anti-dsDNA positivity and renal involvement. Serology was nonreactive in all the cases. ITP is a manifestation of SLE and it was particularly important in case1 as the classical skin manifestations were absent. Platelet count improved with steroid therapy. Case 2 presented with symmetrical inflammatory polyarthritis, leukopenia with negative RA Factor, and anti-CCP antibody. ANA was positive but antidsDNA was negative and anti-SSA was positive. Patient did not have renal involvement and improved on steroids. There was synovitis of more than two joints with swelling, tenderness and morning stiffness of approximately $1 \mathrm{~h}$. Case 3 presented with malar rash and photosensitivity with ANA positivity, but anti-dsDNA was negative with anti SSA positivity. Renal involvement was absent with presence of leukopenia. ${ }^{15}$ ANA Titre $\geq 1: 80$ on HEP2 is the entry criteria in the new classification and it's absence rules out SLE. When ANA is positive, additive criteria are applied which if present even on one occasion, it is sufficient to diagnose SLE with at least one clinical criteria with $\geq 10$ points. It is also specified that the criteria may not occur simultaneously. Clinical domains and criteria are constitutional (fever), hematologic (leukopenia, thrombocytopenia, and autoimmune hemolysis), neuropsychiatric (delirium, psychosis, and seizure), mucocutaneous (non-scarring alopecia, oral ulcers, subacute cutaneous lupus erythematosus or discoid lupus erythematosus, and acute cutaneous lupus), serosal (pleural or pericardial effusion, and acute pericarditis), musculoskeletal (joint involvement), and renal (proteinuria

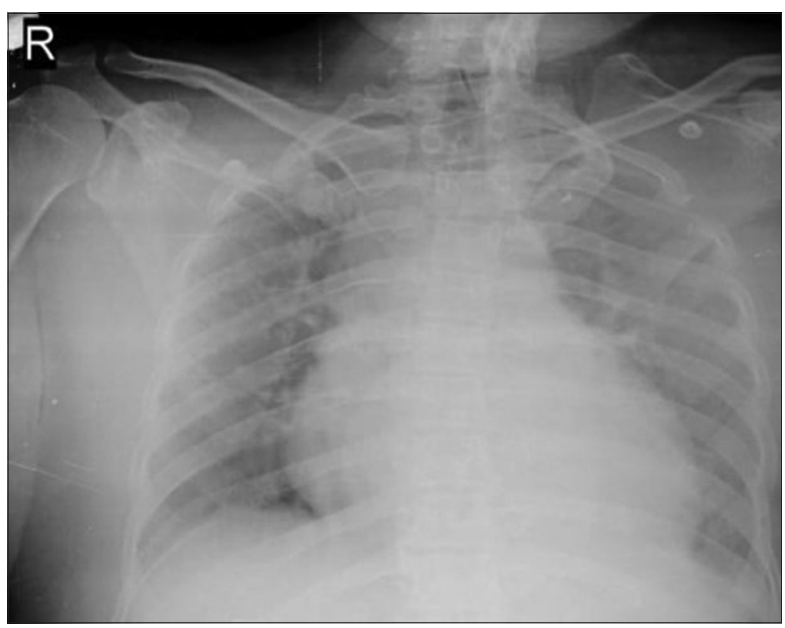

Figure 1: Case 3 systemic lupus erythematosus patient initial chest X-ray

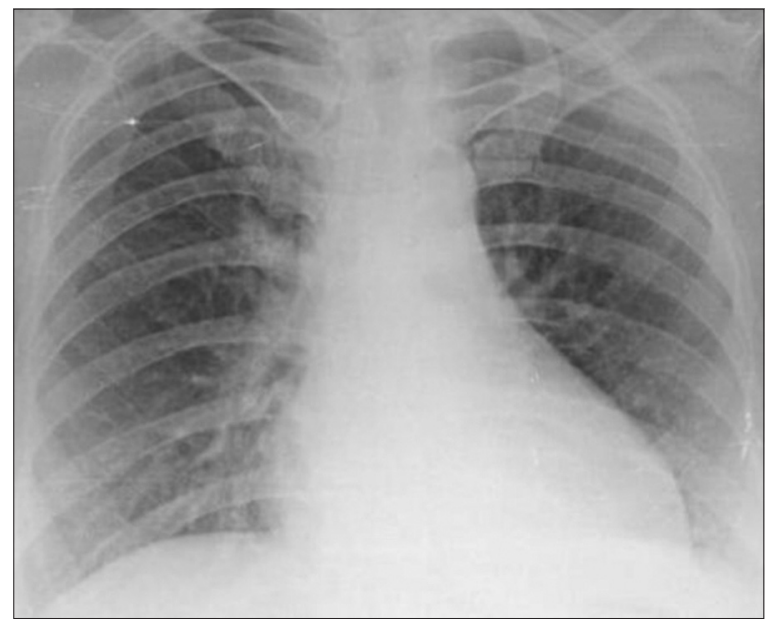

Figure 2: Case 3 systemic lupus erythematosus patient chest X-ray after starting steroids 


\section{Table 1: Clinical and laboratory features of SLE patients}

\begin{tabular}{llll}
\hline Patients & Clinical features & Laboratory findings & Diagnosis \\
\hline 1 & $\begin{array}{l}\text { Thrombocytopenia, bilateral } \\
\text { pitting edema }\end{array}$ & $\begin{array}{l}\text { Platelet count - } 90,000 / \mathrm{mm}^{3} \text {, urinary } \\
\text { protein excretion-1 g/24 h, Anti-dsDNA } \\
\text { positive, reduced C3 }\end{array}$ & $\begin{array}{l}\text { SLE presenting as ITP with renal involvement and } \\
\text { anti-dsDNA positivity }\end{array}$ \\
2 & $\begin{array}{l}\text { Joint pain with synovitis, } \\
\text { non-scarring alopecia }\end{array}$ & $\begin{array}{l}\text { Leukopenia, Negative anti-dsDNA, anti } \\
\text { SSA positivity, lack of renal involvement }\end{array}$ & $\begin{array}{l}\text { SLE with synovitis, alopecia and leukopenia, anti- } \\
\text { dsDNA negative, lack of renal involvement }\end{array}$ \\
& $\begin{array}{l}\text { Photosensitivity, malar rash } \\
\text { and non-scarring alopecia }\end{array}$ & $\begin{array}{l}\text { Leukopenia, polyserositis, anti-dsDNA } \\
\text { negativity, anti SSA positivity, reduced C3 }\end{array}$ & $\begin{array}{l}\text { SLE with skin and hematological manifestations, } \\
\text { anti-dsDNA negative with polyserositis and no } \\
\text { renal involvement }\end{array}$
\end{tabular}

SLE: Systemic lupus erythematosus, ITP: Idiopathic thrombocytopenic purpura

$\geq 0.5 \mathrm{~g} / 24 \mathrm{~h}$ and renal biopsy score). The immunology domains and criteria are antiphospholipid antibodies (anti Cardiolipin, anti Beta2 GP1, and Lupus anticoagulant), Complement proteins (low C3 and/or low C4), and SLE specific antibody (anti ds-DNA, anti-Smith antibody). The new criteria tried to identify SLE at an early stage. So these cases highlight the correlation of renal involvement with anti ds DNA positivity. ${ }^{16}$ Hypocomplementemia was associated with anti-SS A in SLE patients, but antiphospholipid antibodies were absent in them as described in the study by Aurora Menedenez et al which was also evident in the case series. The patients who are persistently anti ds DNA negative have polyserositis as an atypical clinical feature. ${ }^{17}$

\section{CONCLUSION}

The importance of the case series is the lack of renal manifestations in anti-dsDNA negative SLE patients with polyserositis in anti SSA positive lupus cases with antidsDNA negativity (Table 1). The SSA/SSB positive patients should be followed up for monitoring the development of sicca symptoms and anti-dsDNA levels should be checked for conversion from anti-dsDNA negativity to positivity, thus altering the prognosis. The patients who are persistently anti-dsDNA negative have polyserositis as an atypical clinical feature. Patient did not allow to take photographs, but consent was taken to present the case.

\section{ACKNOWLEDGEMENT}

Department of General Medicine, Jagannath Gupta Institute of Medical Sciences and Hospital, Budge Budge, Kolkata, West Bengal, India.

\section{REFERENCES}

1. Sherer Y, Gorstein A, Fritzler MJ and Shoenfeld Y. Autoantibody explosion in systemic lupus erythematosus: More than 100 different antibodies found in SLE patients. Semin Arthritis Rheum. 2004;34(2):501-537.

https://doi.org/10.1016/j.semarthrit.2004.07.002

2. Tsokos GC. Systemic lupus erythematosus. N Engl J Med.
2011;365(22):2110-2121.

https://doi.org/10.1056/NEJMra1100359

3. Aringer $M$ and Vital $E$. Lots of autoantibodies equal lupus? Arthritis Res Ther. 2013;15(1):102.

https://doi.org/10.1186/ar4126

4. Colasanti T, Maselli A, Conti F, Sanchez M, Alessandri C, Barbati $C$, et al. Autoantibodies to estrogen receptor $\alpha$ interfere with T lymphocyte homeostasis and are associated with disease activity in systemic lupus erythematosus. Arthritis Rheum. 2012;64(3):778-787.

https://doi.org/10.1002/art.33400

5. Alessandri C, Barbati C, Vacirca D, Piscopo P, Confaloni A, Sanchez M, et al. T lymphocytes from patients with systemic lupus erythematosus are resistant to induction of autophagy. FASEB J. 2012;26(11):4722-4732.

https://doi.org/10.1096/fj.12-206060

6. Isenberg DA, Manson JJ, Ehrenstein MR and Rahman A. Fifty years of anti-ds DNA antibodies: Are we approaching journey's end?. Rheumatology (Oxford). 2007;46(7):1052-1056.

https://doi.org/10.1093/rheumatology/kem112

7. Cozzani E, Drosera M, Gasparini G and Parodi A. Serology of lupus erythematosus: Correlation between immunopathological features and clinical aspects. Autoimmune Dis. $2014 ; 2014: 321359$

https://doi.org/10.1155/2014/321359

8. Arbuckle MR, McClain MT, Rubertone MV, Scofield RH, Dennis GJ, James JA, et al. Development of autoantibodies before the clinical onset of systemic lupus erythematosus. N Engl J Med. 2003;349(16):1526-1533. https://doi.org/10.1056/NEJMoa021933

9. Foster MH, Cizman B and Madaio MP. Nephritogenic autoantibodies in systemic lupus erythematosus: Immunochemical properties, mechanisms of immune deposition, and genetic origins. Lab Invest. 1993;69(5):494-507.

10. Pascual V, Farkas $L$ and Banchereau J. Systemic lupus erythematosus: All roads lead to type I interferons. Curr Opin Immunol. 2006;18(6):676-682.

https://doi.org/10.1016/j.coi.2006.09.014

11. ter Borg EJ, Horst G, Hummel EJ, Limburg PC and Kallenberg CG. Measurement of increases in anti-double-stranded DNA antibody levels as a predictor of disease exacerbation in systemic lupus erythematosus. A long-term, prospective study. Arthritis Rheum. 1990;33(5):634-643.

https://doi.org/10.1002/art.1780330505

12. Linnik MD, Hu JZ, Heilbrunn KR, Strand V, Hurley FL, Joh T, et al. Relationship between anti-double-stranded DNA antibodies and exacerbation of renal disease in patients with systemic lupus erythematosus. Arthritis Rheum. 2005;52(4):1129-1137. https://doi.org/10.1002/art.20980 
13. Hahn BH. Antibodies to DNA. N Engl J Med. 1998;338(19):1359-1368.

https://doi.org/10.1056/NEJM199805073381906

14. Rao L, Liu G, Li C, Li Y, Wang Z, Zhou Z, et al. Specificity of anti-SSB as a diagnostic marker for the classification of systemic lupus erythematosus. Exp Ther Med. 2013;5(6):1710-1714. https://doi.org/10.3892/etm.2013.1051

15. Aringer $M$, Costenbader K, Daikh D, Brinks R, Mosca $M$, Ramsey-Goldman R, et al. 2019 European league against rheumatism/American college of rheumatology classification criteria for systemic lupus erythematosus. Ann Rheum Dis. 2019;78(9):1151-1159. https://doi.org/10.1136/annrheumdis-2018-214819

16. Menéndez A, Gómez J, Caminal-Montero L, Díaz-López JB, Cabezas-Rodríguez I and Mozo L. Common and specific associations of anti-SSA/Ro60 and anti-Ro52/TRIM21 antibodies in systemic lupus erythematosus. ScientificWorldJournal. 2013;2013:832789.

https://doi.org/10.1155/2013/832789

17. Conti F, Ceccarelli F, Perricone C, Massaro L, Marocchi E, Miranda F, et al. Systemic lupus erythematosus with and without anti-dsDNA antibodies: Analysis from a large monocentric cohort. Mediators Inflamm. 2015;2015:328078.

https://doi.org/10.1155/2015/328078

\section{Authors Contribution:}

SM- Diagnosis, concept, manuscript writing; SS- Diagnosis, manuscript correction; BM- Diagnosis and manuscript writing; SG- Research and providing pictures

Work attributed to:

Jagannath Gupta Institute of Medical Sciences and Hospital, Budge Budge, Kolkata, West Bengal, India.

\section{Orcid ID:}

Dr. Somnath Maitra - (D) https://orcid.org/0000-0001-7906-3570

Dr. Swapan Sarkar- (D https://orcid.org/0000-0003-0007-052X

Dr. Biswaroop Mukherjee- (1) https://orcid.org/0000-0002-0112-8941

Dr. Suprotim Ghosh- (D https://orcid.org/0000-0002-2632-0980

Source of Support: Nil, Conflict of Interest: None. 